核融合研究为 6 巻为 4 号 1961 年 4 月

\title{
Binary Correlation Corrections for the \\ Diclectric Constant of Electron Plasma
}

市川芳佐藤 正知 (日大理工 $)^{*}$

§1. 序論

高湓ブラズマ内に生ずるブラズマ振動の問題について、特に與味があるのは、その減衰過程、 或いは 朸起過程の機構である。減害についていえば、macros copic な流体力学的取扱い

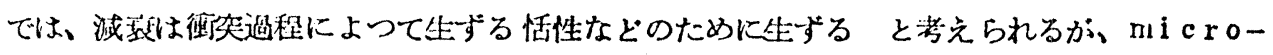
scopi c な統計力学的狂扱いでは、粒子間の衝突効果を完全に然視したいかゆるBoItzmannVIas ov 方程式から、プラズマ振動に対する Landau damping が涪かれている(1) 然 し、Landau damping の物理的内容については、しばしば論争の種になつている。この よ5に色くな意見が出てくる原因は、一つには Landau による理諭の展開が”数学的“で あつた事と、も5一方で、“物理的“には、BoItzmann 方程式において衝突項を無視する 極限に対与る流体力学的類推が余りに直钼的に用いられている型とい5二つ理由によるといえよう。

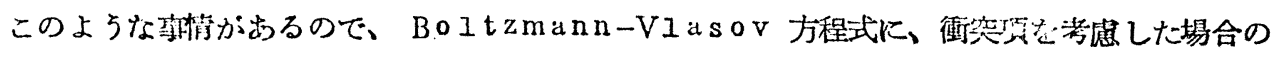

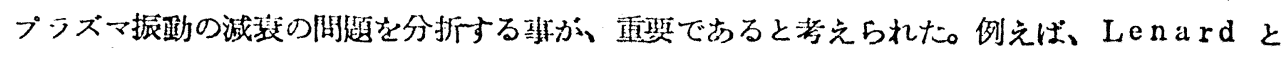
Bernstein2) は、衝乫項として

$$
\begin{aligned}
& \frac{\partial f}{\partial \mathrm{t} \operatorname{col} I}=\beta \frac{\partial}{\partial \mathrm{v}} \cdot\left[\mathrm{v} f_{1}+u_{0} 2 \frac{\partial f_{1}}{\partial \mathrm{v}}\right] \\
& \beta=\mathrm{g} \omega_{\mathrm{p}} \quad \mathrm{g}^{2}=\left(\mathrm{e}^{2} / \kappa \mathrm{T}\right)^{3} \mathrm{n}
\end{aligned}
$$

の形を用いて、ブラズマ振動の減衰を諭じた。彼等によれば、ブラズマ振動の減衰係数 とは、 $\beta=0$ の㘯合にはLandau damping $r_{L}$

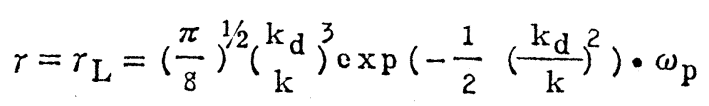

でむたえられi $\beta \neq 0$ の場合には

$$
r=\beta / 2
$$

剧註 ※ Y.H.Ichikawa, M. Sato (Department of Physics Faculty of Engincering Nihon Universty.) 
Binary Correlation Corrections for the Dielectric Constant of Electron Plasma

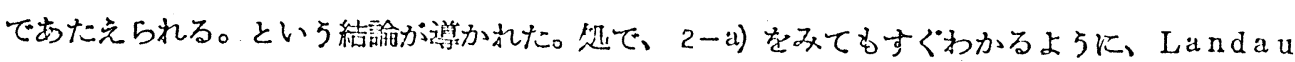

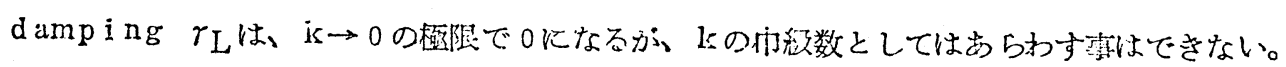

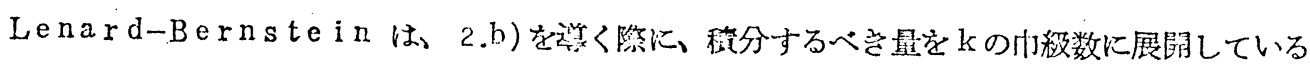
ため、Landau damping をむた党る pole からの等与が全く洗い流されてしなつた

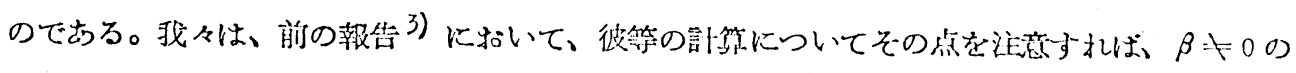
場合、2.b)の代りに

$$
r=r_{L}+\frac{\beta}{2}
$$

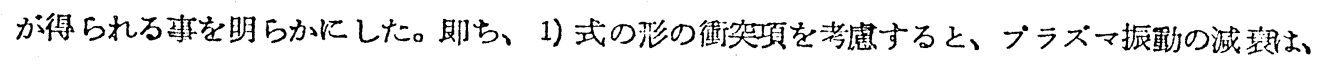
La nda u 減衰と衝突減琵の両力の減琵道程からの等与を含む。

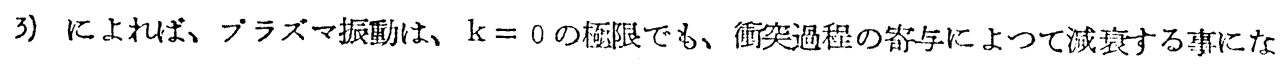
るがこれは、物理的に考光ると不合理である。Lenard-Bernsteinは、クーロン相互 作用による小角散乱の効果を、1）のような Fokker-Planck 型の衝突項でむらわした

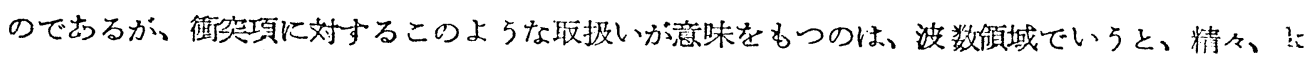
$k \gtrsim k_{D}$ の䉇囲であつて、 $k \ll k_{D}$ の領域に対しては、1)の型の街突項は適用できない。長

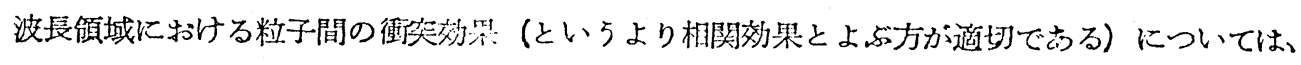
我ふの一人か B-B-G-K-Y の階級方程式に基づいて研究し、粒子間の相関效果が 長波長の 極限 $(k \rightarrow 0)$ では、ブラズマ振動に対して

$$
r_{\text {corr }}=0.03 \mathrm{~g}\left(\mathrm{k} / \mathrm{k}_{\mathrm{d}}\right)^{2} \cdot \omega_{\mathrm{p}}
$$

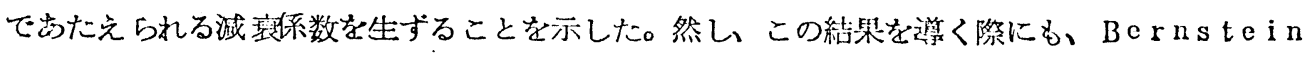
等と同様、kの小さい箕域での漸近展開を用いているため、必然的にLand a u d amping の 㝒与を搭ててしまつている。そこで、前の報告では、Lcnard-Bernstein の研究に対す る我々の批判の筋道を辿つてみると、粒子間の相関効果を正しく考虑すると、ブンズマ振動の減 容係数は、3)で $\beta / 2$ を）でおきかえて

$$
r=r_{L}+r_{\text {corr }}
$$

であたえられるであろう、という予测を述へた。この諭文の目的は、契際にこの予想が正しい拆 を示すことである。 


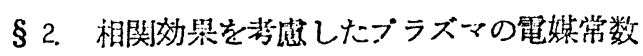

外部からの靦乱に対するブラズマのresponse は、ブラズマの電绦常数がオかれば完全に

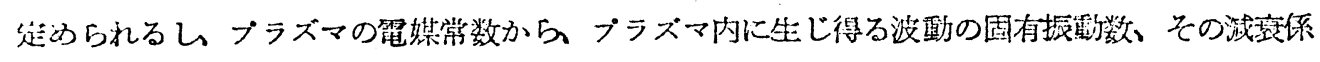

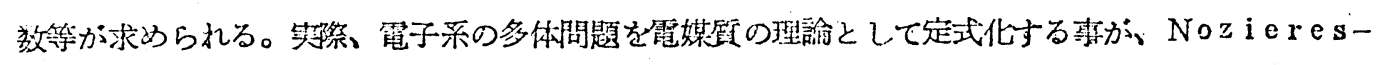
Pines 等の一連の斫究 ${ }^{5)}$ に打いて進められ、問題の物理的内容を理解し、従来の各種の近似 の関係等についで理解を助けるために特に有妨でむることが知られている。それ故、我々るこ

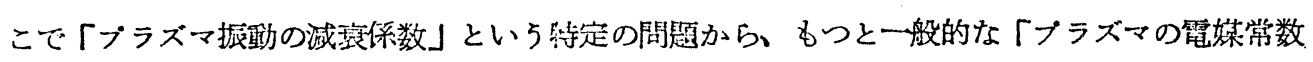
の決定」という問題化切りふ宇よう。

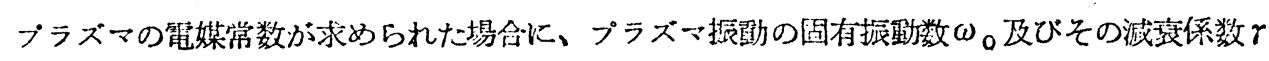
がどのようにして定められるかという点については、最近 Nakaj ima田によつて明快な理論 が展䦎されている。電媒管数とが

$$
\varepsilon(k, \omega)=\varepsilon_{r}(k, \omega)+i \varepsilon_{i}(k, \omega)
$$

としてあたえられるならば、ブラズマ振動の圆有振動数い。は

$$
\varepsilon_{\mathbf{r}}\left(\mathbf{k}, \omega_{0}\right)=0
$$

の根として定まり、その減器係数ては

$$
r=\varepsilon_{\mathrm{i}}\left(k, \omega_{\alpha}\right) / \partial \varepsilon_{\mathrm{r}}\left(\mathbf{k}, \omega_{\alpha}\right) / \partial \omega_{0}
$$

であた兄られる。粒子間の相関效果を取り入れた電媒常数を求める䐂ができれば、8)からブラズ マ振野の減激係数を定める梦ができる。

框関效果を取り入れた篦媒常数を求めるために、粒子間の相間效棵を考虑して I chikawa によつて導かれた方程式

$$
\begin{aligned}
& \left(\frac{\partial}{\partial t}+i k \circ v\right) f_{1}(k, v, t)+\frac{e}{m} \frac{\partial}{\partial v}\left\{E^{*}(k, v, t) f_{0}(v)\right\}=0 \\
& \mathbb{E}^{*}(k, v ; t)=E_{v i}(k ; t)+\delta E(l, v ; t) \\
& \mathbb{E}_{v i}(k ; t)=-i k\left(4 \pi \mathrm{e} / k^{2}\right) \cdot \int f_{1}\left(k, v^{\prime} ; t\right) d v^{\prime}
\end{aligned}
$$


Binary Correlation Corrections for the Dielestric Constunt of Blectron Plasma

$$
\begin{gathered}
\delta E(k, v ; t)=i\left(\frac{e^{3}}{k T}\right) \frac{1}{k^{2}} \int d \omega e^{-i \omega t} \int d i \frac{i}{l^{2}} \\
\frac{G(I-i, i ; \omega ; v)}{\Delta(k-i, i ; \omega ; v)} \cdot \int f_{1}\left(I, v^{1} ; \omega\right) d y^{\prime}
\end{gathered}
$$

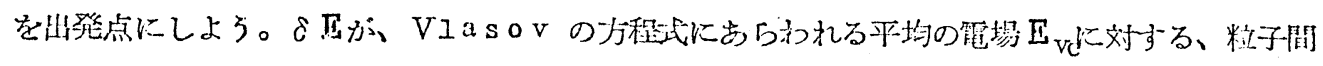

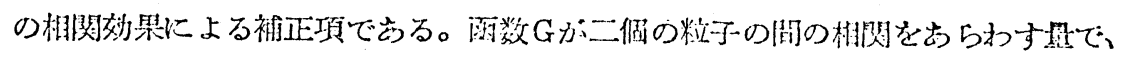

$$
\begin{aligned}
& \left.G(k-i, i ; \omega ; v)=i \int d \nabla^{\prime} f_{0}\left(\nabla^{\prime}\right) \delta_{+}(k-i) \cdot v-i \circ v^{\prime}\right) \circ \\
& {\left[(\mathrm{k} \circ \mathrm{v}) \chi(\mathrm{i})+\left(\mathrm{k} \bullet \mathrm{v}^{\prime}\right)\right]} \\
& \chi(i)=\frac{-k_{d^{2}} / n}{l^{2}+k_{d}^{2}} \\
& \delta_{+}(\mathrm{x})=\int_{0}^{\infty} \mathrm{d} \tau \mathrm{e}^{\mathrm{i} x \tau}
\end{aligned}
$$

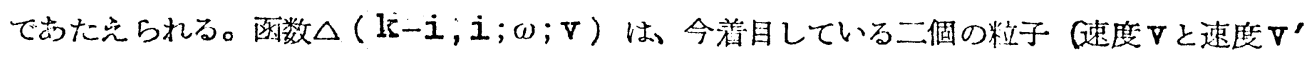
ともつている)の間の相互作用が、その間に介在する为三の粒子によつて s c r e en さ扎る效 果を示す量で、

$$
\begin{aligned}
& \Delta(\mathrm{l} \circ \mathrm{i}, \mathrm{i} ; \omega ; \mathrm{v})=1-\mathrm{i} \frac{4 \pi \mathrm{e}^{\mathrm{i}}}{\mathrm{m}} \frac{1}{\ell^{2}} \int \delta_{+}\left(\omega-(k-i) \mathrm{v}-i \mathrm{v}^{\prime}\right) i \cdot \\
& \frac{\partial}{\partial \mathrm{v}} f_{0}\left(\mathrm{v}^{\prime}\right) \mathrm{d} \mathrm{v}^{\prime}
\end{aligned}
$$

で定学される。

$$
\begin{aligned}
& \Delta(\mathbf{k}-i, i ; \omega ; v)=1+\frac{k_{d}{ }^{2}}{\ell^{2}}+
\end{aligned}
$$

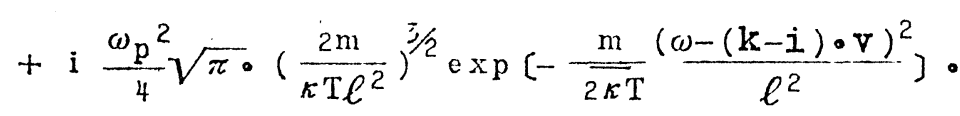

$$
\begin{aligned}
& (\omega-(k-i) \cdot v) \cdot \operatorname{Er} f\left(i \sqrt{\frac{m}{2 k T \ell^{2}}}(\omega-(k-i) v)\right) \\
& +i \sqrt{\frac{\pi}{2}} \cdot{ }_{\omega_{p}}^{\omega-(k-i) \cdot v}\left(\frac{k_{d}}{\ell}\right)^{3} \exp \left[-\frac{m}{2 \kappa T} \frac{(\omega-(k-i) \cdot v)^{2}}{\ell^{2}}\right]
\end{aligned}
$$


となる。

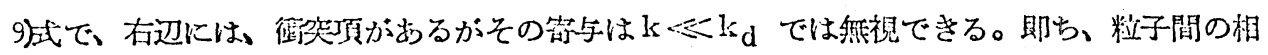

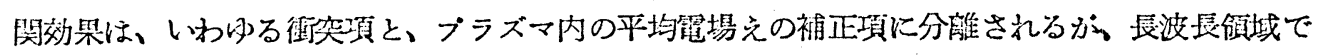

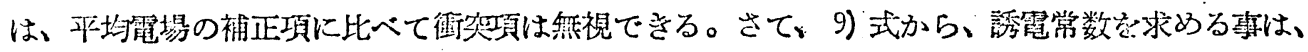

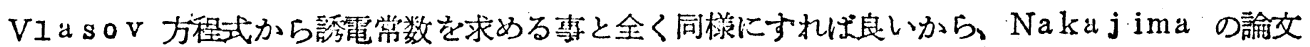
に従つてかんじようずれば、次のような結果を得る。

$$
\begin{aligned}
& \varepsilon(k, \omega)=\varepsilon_{r}(k, \omega)+i \varepsilon_{i}(k, \omega) \\
& \varepsilon_{\mathrm{r}}(\mathrm{l}, \omega)=1-\frac{4 \pi \mathrm{e}^{2}}{\mathrm{~m}} \frac{1}{\mathrm{k}^{2}} \mathrm{p} \int \frac{1}{\mathrm{~F}_{\mathrm{O}} \mathrm{v}-\omega} \mathrm{k} \cdot \frac{\partial}{\partial \mathrm{v}} f_{\mathrm{o}}(\mathrm{dv} \\
& +\frac{4 \pi \mathrm{e}^{2}}{\mathrm{~m}} \frac{1}{\mathrm{k}^{2}} \mathrm{p} \int \frac{1}{\mathrm{~K} \cdot \mathrm{v}-\omega} \cdot \frac{\partial}{\partial \mathrm{v}}\left\{\mathrm{I}_{\mathrm{r}}(\mathrm{k}, \mathrm{v} ; \omega) f_{\mathrm{o}}(\mathrm{v})\right\} \mathrm{dv} \\
& -\frac{4 \pi \mathrm{c}^{2}}{\mathrm{~m}} \frac{1}{\mathrm{k}^{2}} \pi \int \delta(\mathrm{k} \cdot \mathrm{v}-\omega) \frac{\partial}{\partial \mathrm{v}}\left\{\mathrm{K}_{\mathrm{i}}(\mathrm{k}, \mathrm{v} ; \omega) f_{0}(\boldsymbol{\nu})\right\} \mathrm{d} \mathbf{v} \\
& \varepsilon_{i}(k, \omega)=-\frac{4 \pi c^{2}}{m} \frac{1}{k^{2}} \int \delta(k \cdot v-\omega) k_{0} \cdot \frac{\partial}{\partial v} f_{0}(v) d v \\
& +\frac{4 \pi \mathrm{e}^{2}}{\mathrm{~m}} \frac{1}{\mathrm{k}^{2}} \pi \int \delta(\mathrm{k} \cdot \mathrm{v}-\omega) \frac{\partial}{\partial \mathrm{v}}\left\{\mathrm{K}_{\mathrm{r}}(\mathrm{k}, \mathrm{v} ; \omega) f_{\mathrm{o}}(\mathrm{v})\right\} \mathrm{dv} \\
& +\frac{4 \pi \mathrm{e}^{2}}{\mathrm{~m}} \frac{1}{\mathrm{k}^{2}} \mathrm{p} \int \frac{1}{\mathrm{k} \cdot \mathrm{v}-\omega} \frac{\partial}{\partial \mathrm{v}}\left\{\mathrm{K}_{\mathrm{i}}(\mathrm{K}, \mathrm{v} ; \omega) f_{\mathrm{o}}(\mathrm{v})\right\} \mathrm{d} \mathrm{v}
\end{aligned}
$$

但し、

$$
K(k, v ; \omega)=\left(\frac{e^{2}}{\kappa T}\right) \frac{1}{2 \pi^{2}} \int \mathrm{d} i \frac{i}{\ell^{2}} \frac{G(k-i, i ; \omega ; v)}{\Delta(k-i, i ; \omega ; v)}
$$

で $\mathrm{K}_{\mathrm{r}} ， \mathrm{~K}_{\mathrm{i}}$ はそれぞれKの笑数部及び虚数部である。

$\varepsilon_{\mathrm{r}}, \varepsilon_{\mathrm{i}}$ のそれぞれの为一項は、VIasov の方程式の觔から得られる部分で、多体閴題の 方の言葉でいえば、random phase の近似（R.P.A）の渻囲で求められる電媒常数

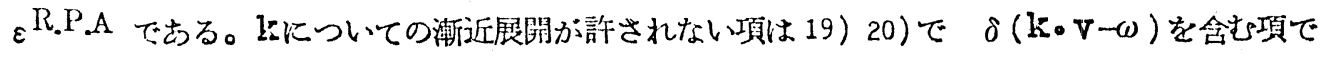
ある。奏際にこう)の为一項は

$$
\varepsilon_{\mathrm{l}}^{(1)}(\mathrm{k}, \omega)=\sqrt{\frac{\pi}{2}}\left(\frac{\mathrm{k}_{\mathrm{d}}}{\mathrm{k}}\right)^{3} \exp \left(-\frac{1}{2}\left(\frac{\mathrm{k}_{\mathrm{d}}}{\mathrm{k}}\right)^{2}\right)
$$


Binary Correlation Corrections for the Dielectric Constant of Electron Plasma

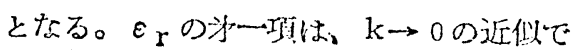

$$
\varepsilon_{r}^{(1)}(k, \omega)=1-\left(\frac{\omega p}{\omega}\right)^{2}
$$

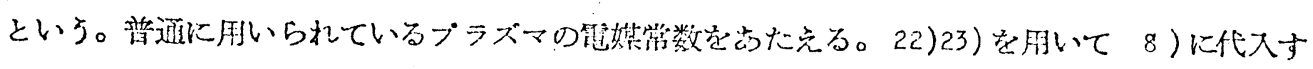
ると、

$$
r^{(1)}=\sqrt{\frac{\pi}{8}}\left(\frac{k_{e}}{k}\right)^{3} \exp \left(-\frac{1}{2}\left(\frac{k}{k}\right)^{2}\right) \omega_{p}
$$

が結果する。

§3. プラズマ振動の娍珵係数

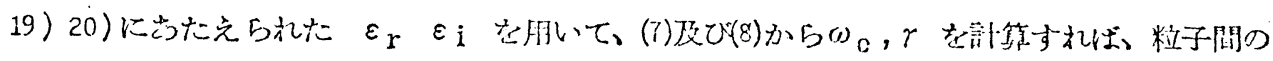

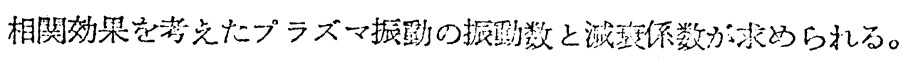

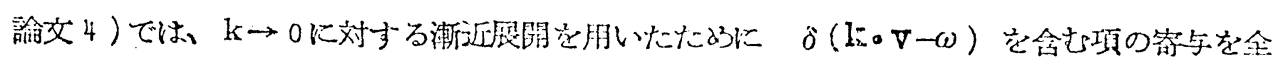
部落していたが、その他に、計算の遂行のために、为三の粒子の存在にする二個の䊀于の䦌の

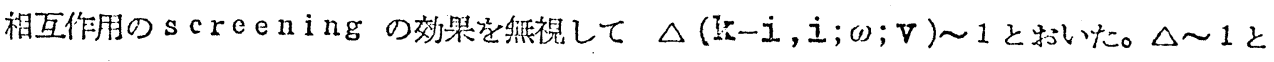
特けば、20)の矛三项は

$$
\begin{aligned}
& \varepsilon_{\mathrm{i}}^{(3)}(\mathrm{k}, \omega)=\pi\left(\omega_{\mathrm{p}}{ }^{2} \mu\right)\left(4 \pi \mathrm{e}^{2} / \kappa_{\mathrm{T}} \mathrm{T}\right) \cdot \frac{1}{8 \pi^{3}} \int \mathrm{d} i \frac{(\dot{i} \cdot \theta)}{\ell^{2}} \int \mathrm{d} \mathrm{v} f_{0}(\mathrm{v}) \\
& \text { - } \frac{1}{(\omega-\mathrm{k} \cdot \mathrm{v})^{2}} \int \delta\left(\omega-\left(\mathrm{k}-\mathrm{v} \cdot \mathrm{v}-\mathbf{i} \mathrm{v}^{\prime}\right)\{(\boldsymbol{\theta} \mathrm{\nabla}) \chi(\mathrm{i})\right. \\
& \left.+\left(\theta \cdot v^{\prime}\right) \chi(l i-i)\right\} f_{0}\left(v^{\prime}\right) d v^{\prime}
\end{aligned}
$$

となる。この卦式と、論交 4)の93)式をくらべてみれば、 $r_{\mathrm{corr}}$ は将にこの頃の染与である ことがわかる。この項を計算すると

$$
\varepsilon_{\mathrm{i}}^{(3)}(\mathrm{k}, \omega) \approx 0.06\left(\frac{\mathrm{k}}{\mathrm{k}_{\alpha}}\right)^{22} \cdot \mathrm{g}
$$

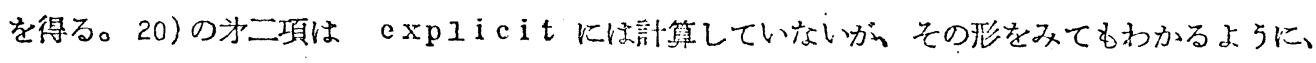
それは一般に $\mathrm{F}\left(\mathrm{k} / \mathrm{k}_{\mathrm{d}}\right)$ をkの任意の函数として

$$
\varepsilon_{\mathrm{i}}^{(2)}(k, \omega) \approx F\left(\mathrm{k} / \mathrm{k}_{\mathrm{d}}\right) \varepsilon_{\mathrm{i}}^{(1)} \mathrm{g}
$$


市川。佐藤

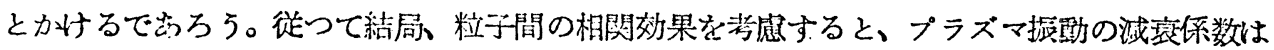

$$
r=\{1+F(k) g\} r_{L}+0.03 g \cdot\left(\frac{k}{k_{d}}\right)^{2} \omega_{p}
$$

であたえられる票がわかる。それ故、論交 4)で示したように、kの小さい領域ではｇについて高

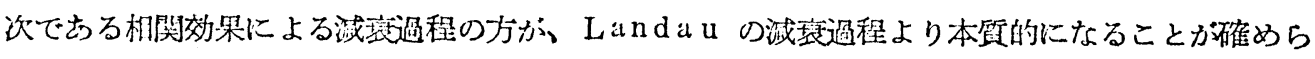

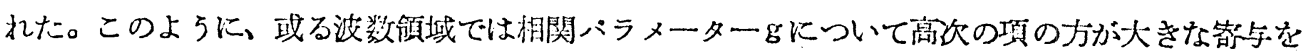
もつようになるという势は、クーロン相互作用による長距敋相関の効果の特殊性のあらわれであ る。

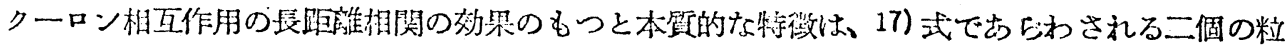
子閶の相互作用を s c r c e n する为三の粒子の影嚮である。此の論交では、前の報告で述へた予 测が舁際正しい事を示す議論の筋道を明らかにする冓を目的としたので、そのような粒子間の相

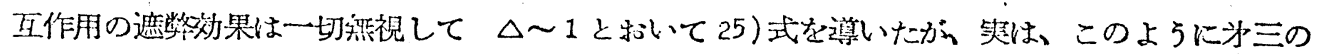

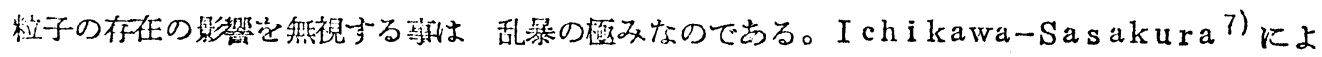

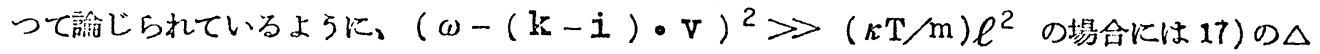
は

$$
\Delta \approx I-\frac{\omega_{p}^{2}}{(\omega-(I-i) \cdot v)^{2}}+i \Delta_{i}
$$

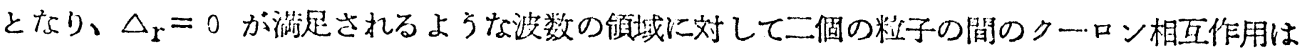
screen ざれないで、むしろ enhance される京になる。このよ5な相互作用の

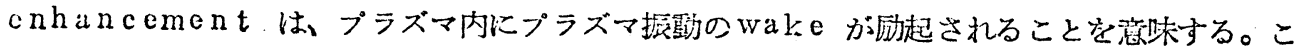
のような相互作用の立鵬的 enhancement が ブラズマの電媒常数の性撕にどのような影 響を持つかくわしく調べなければならない。この点に夙する椧討は次の機会にゆずる。

1) L.Landau: J. of Phys USSR 10(1946),25

2) A.Lenard and Ira.Bernstein: Phys.Rev.112(1958),1456

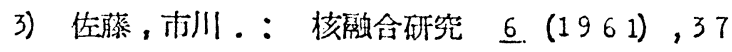

4) Y.H.I chikawa : Prog.Theoret.Phys.24(1960),1083

5) P.Nozieres and D.Pines: Nuouo Cimento 9 (1958)470, Phys.Rev.109 (1958) .762

6) 中 嶋 : 物性諭研究 2 集 8 巻 $(19660) 340$

7) I chikawa, Sasakura: Prog.Theoret.Phys. 